\title{
Fine structure of the rupture zone of the April 26 and 27, 1997, Northridge aftershocks
}

\author{
Anupama Venkataraman, ${ }^{1}$ Jim Mori, ${ }^{2}$ Hiroo Kanamori, ${ }^{1}$ and Lupei $\mathrm{Zhu}^{3}$
}

\begin{abstract}
We investigated the rupture geometry of two $M_{w} \sim 4.5$ earthquakes (April 26, 1997, and April 27, 1997) that occurred on the western edge of the aftershock zone of the 1994, $M_{w} 6.7$, Northridge earthquake. Both events have thrust mechanisms with a steep plane dipping $\sim 75^{\circ} \mathrm{SE}$ and a shallow plane dipping $\sim 45^{\circ} \mathrm{NE}$. An empirical Green's function deconvolution followed by a waveform inversion was used to determine the slip distribution of the two events. The inversion results show that the steep plane fits the data slightly better than the shallow plane. The background seismicity (aftershocks of the 1994 Northridge event) in the epicentral region shows the existence of a north dipping fault plane, similar to that of the 1971 San Fernando earthquake. However, the spatial trend of the two April 1997 events and their aftershocks reveals tightly clustered seismicity on a steep plane dipping south. Relative relocation of the April 26 and 27 events shows that the April 27 event ruptured $\sim 1.4 \mathrm{~km} \mathrm{N70}{ }^{\circ} \mathrm{E}$ of the April 26 event and at a slightly shallower depth, i.e., almost along strike and on a steep plane dipping south. These observations suggest that the steep plane is the fault plane of both events. The two events ruptured on a plane which is almost perpendicular to the trend of the regional background seismicity. Thus the seismogenic structure beneath the Transverse Ranges exhibits complexity on scales of a few kilometers. The rupture area for both the April 26 and 27 events is $\sim 1 \mathrm{~km}^{2}$ with a stress drop of at least 20 to 30 bars.
\end{abstract}

\section{Introduction}

The east-west trending Transverse Ranges of southern California are undergoing active north-south shortening. The Transverse Ranges were formed as a result of the compressional stresses associated with the Big Bend in the San Andreas fault. The complex structure and tectonics of the region have been studied using plate motions [Anderson, 1971], leveling data [Thatcher, 1976], geology [Yeats, 1981; Yeats, 1983; Namson and Davis, 1988a,b], seismicity and kinematics [Corbett and Johnson, 1982; Bird and Rosenstock, 1984; Savage et al., 1986; Nicholson et al., 1986] and seismic reflection and seismicity studies [Hadley and Kanamori, 1977, 1978; Humphreys et al., 1984; Webb and Kanamori, 1985; Cheadle et al., 1986; Huang et al., 1996; Ryberg and Fuis, 1998].

\footnotetext{
${ }^{1}$ Seismological Laboratory, California Institute of Technology, Pasadena.

${ }^{2}$ Disaster Prevention Research Institute, Kyoto University, Kyoto, Japan.

${ }^{3}$ Department of Earth Sciences, University of Southern California, Los Angeles.
}

Copyright 2000 by the American Geophysical Union.

Paper number 2000JB900067.

0148-0227/00/2000JB900067\$09.00
The Transverse Ranges to the west of the $1994, M_{w}$ 6.7, Northridge earthquake have a complicated surface geology with faults oriented in different directions [Yeats et al., 1994; Davis and Namson, 1994]. Moreover, there is no simple explanation for the lower geodetic strain rates as compared to the higher geologically measured strain rates in this region [Jackson and Molnar, 1990 Donnellan et al., 1993; Yeats, 1993]. In their study of the Northridge aftershock sequence, Hauksson et al. [1995] see a diffuse distribution of aftershocks in this western part of the aftershock zone. They suggest that these aftershocks occurred on faults that did not rupture in the mainshock. The studies mentioned above indicate that both the surface structure as well as the structure at depth are complicated in this region.

Two moderate earthquakes $\left(M_{w} \sim 4.5\right)$ occurred on April 26 and 27, 1997, in this region (Plate 1). Both events have similar focal mechanisms with one nodal plane dipping $\sim 75^{\circ} \mathrm{SE}$ and the other nodal plane dipping $\sim 45^{\circ} \mathrm{NE}$. Many of the earlier events in the region had similar focal mechanisms and magnitudes, but owing to poorer data quality and fewer stations, no direct determination of slip planes was possible. In this study we use data from the newly deployed dense network of stations (TriNet) to examine the directivity effects of the far-field source time functions of the April 26 and 27,1997 , events. Owing to the proximity of the stations to the event, a high-resolution study of the structure of 
a)

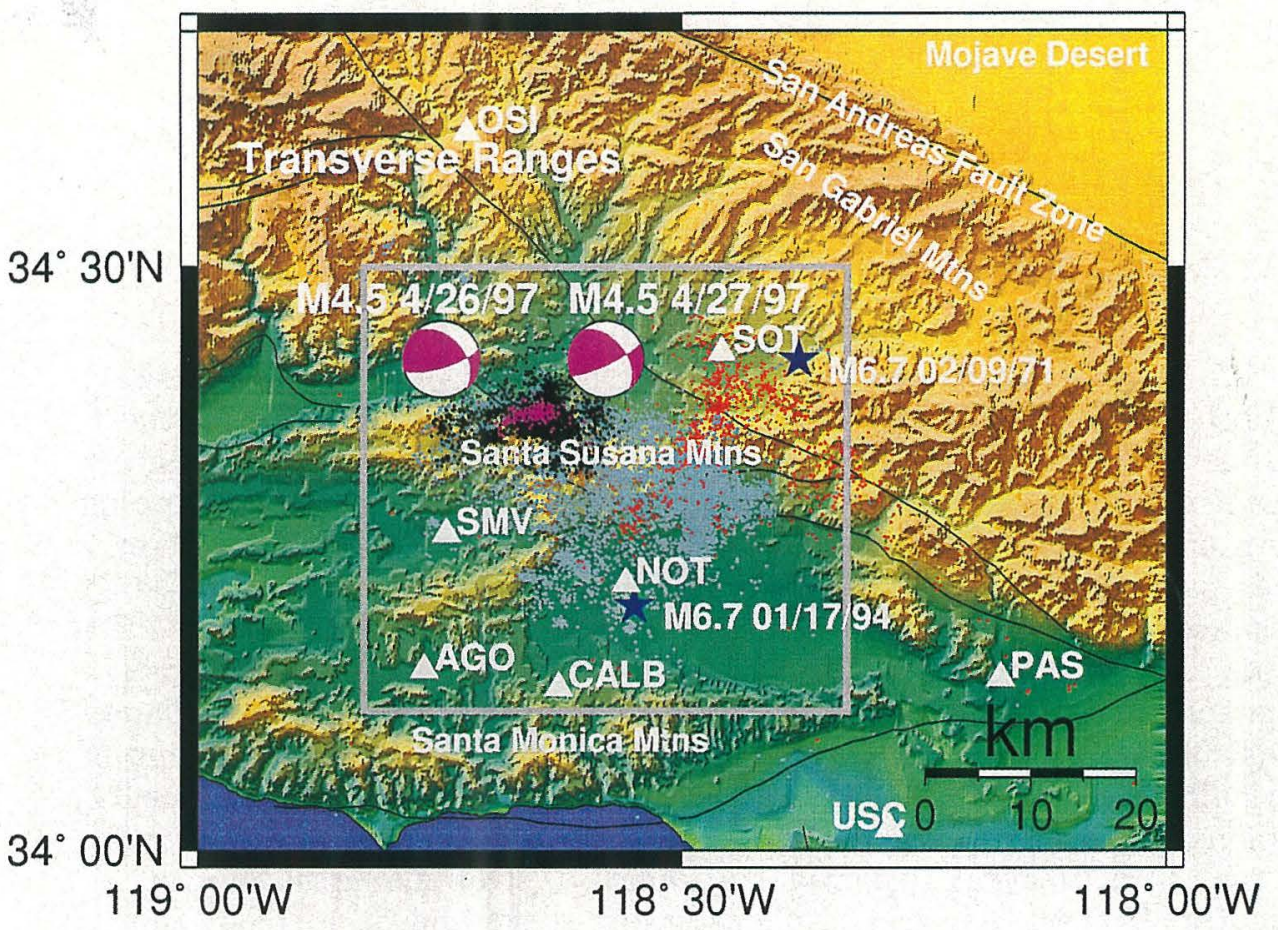

N

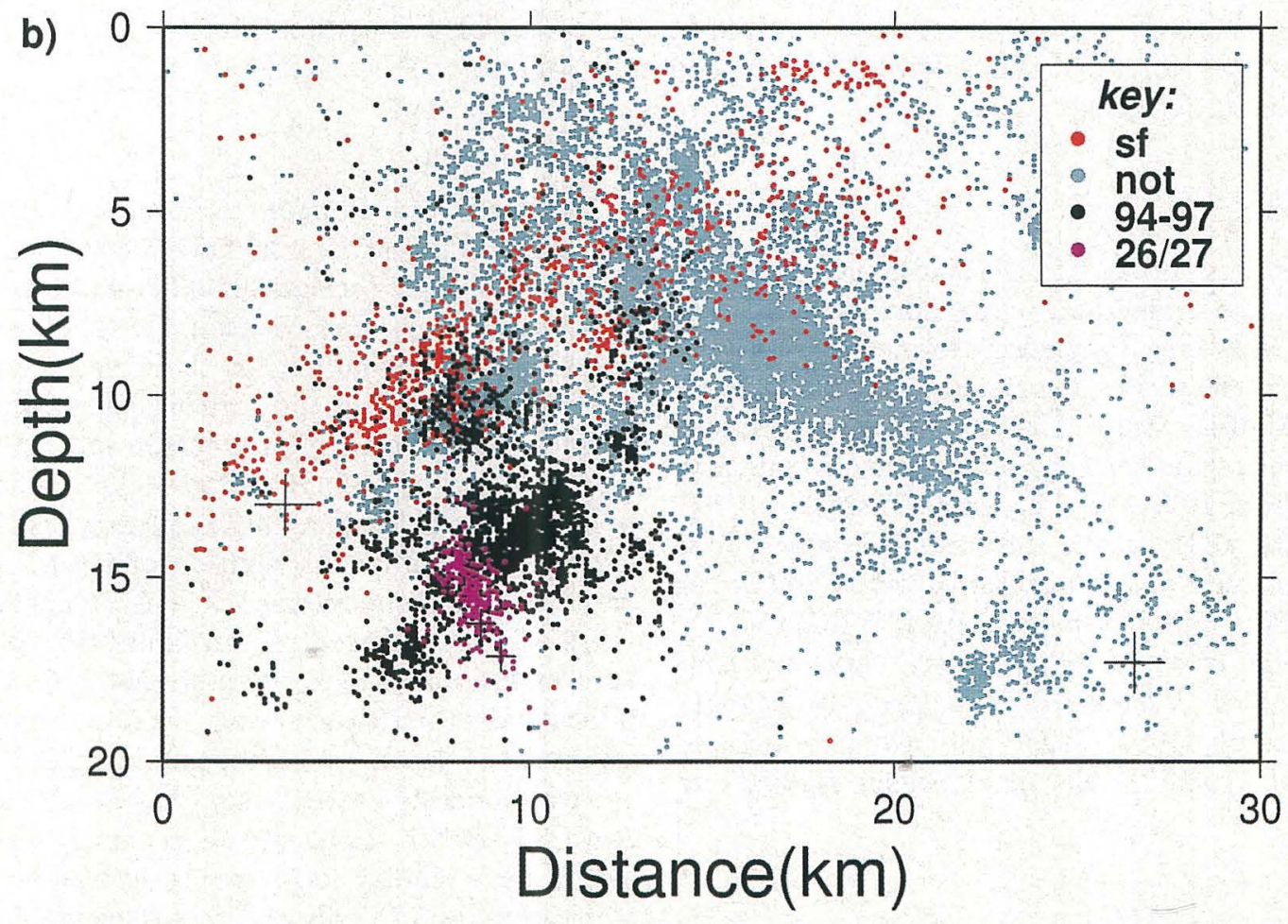

Plate 1. (a) Focal mechanisms (lower hemisphere) and location map of the April 26 and April 27, 1997, earthquakes. Triangles represent seismic stations. The location of the January 17, 1994, Northridge earthquake $\left(M_{w} 6.7\right)$ and the February 9,1971 , San Fernando earthquake $\left(M_{w} 6.7\right)$ are denoted by stars. (b) A cross section of all the well-located aftershocks that were recorded by the Southern California Seismic Network. The gray box in Plate 1a shows the area and orientation of the cross section. The April 1997 events and their aftershocks are shown in purple; the events that were recorded between January 1994 and April 1997 in the western edge of the Northridge aftershock zone are shown in black. The aftershocks of the San Fernando earthquake recorded from February 1971 to mid-April 1971 are shown in red. The aftershocks recorded in the year following the 1994 Northridge event are shown in blue. 
the rupture planes was possible. This helps us to better understand the pattern of faulting in this region.

In sections 2 and 3 of this paper we do a relative relocation of the two April, 1997 events and use a source inversion to determine the mechanism and seismic moment of the two events. In section 4 , we present the results of a Green's function deconvolution (with a positivity constraint) that we used to obtain source time functions. In section 5 we invert these source time functions to determine the slip distribution on the fault plane. In section 6 we perform an aftershock relocation of all the earthquakes that occurred in the region since the 1994 Northridge earthquake.

\section{Data}

The April 26 and 27, 1997, earthquakes were well recorded by the newly deployed TriNet [Mori et al., 1998] stations in southern California. The events had good azimuthal station coverage with five stations at epicentral distances of $\sim 20 \mathrm{~km}$. The data are archived at the Southern California Earthquake Center (SCEC) Data Center. In our analysis, we used velocity and acceleration records for the two mainshocks and high-gain velocity records for the smaller events which were used as empirical Green's functions. The waveforms at sta- tion NOT were corrected for a polarity reversal (the $\mathrm{E}-\mathrm{W}$ and $\mathrm{N}-\mathrm{S}$ components were flipped in the original data).

For both the April 26 and 27 events the displacement waveforms recorded at station SOT are much narrower than those recorded at stations NOT and SMV (Figure 1) and suggest that both events ruptured toward station SOT. The April 27 event appears to be a double event. The location of the April 27 event relative to the April 26 event provides an indication of the rupture geometry of the sequence. We measured the $P$ wave arrival times of the two events at 20 TriNet stations that had good signal to noise ratio and located them relative to each other. The April 27 event is located $\sim 1.4 \mathrm{~km} \mathrm{~N} 70^{\circ} \mathrm{E}$ of the April 26 event (Figure 2) and at a slightly shallower depth. As shown in Figure 2, the relative location of the two events suggests that both events are located on a steeply dipping plane. This observation, coupled with the observed directivity toward station SOT, suggests that the rupture of the whole sequence was probably on the steep nodal plane.

Three $M_{w} \sim 2.7$ aftershocks (origin times April 26, 1997, 1054 UT; April 26, 1007, 1431 UT and April 16, 1997, 1109 UT) of the April 1997 sequece with high signal to noise ratio are shown in Figure 1c. We observe that these aftershocks also exhibit an azimuthal varia-
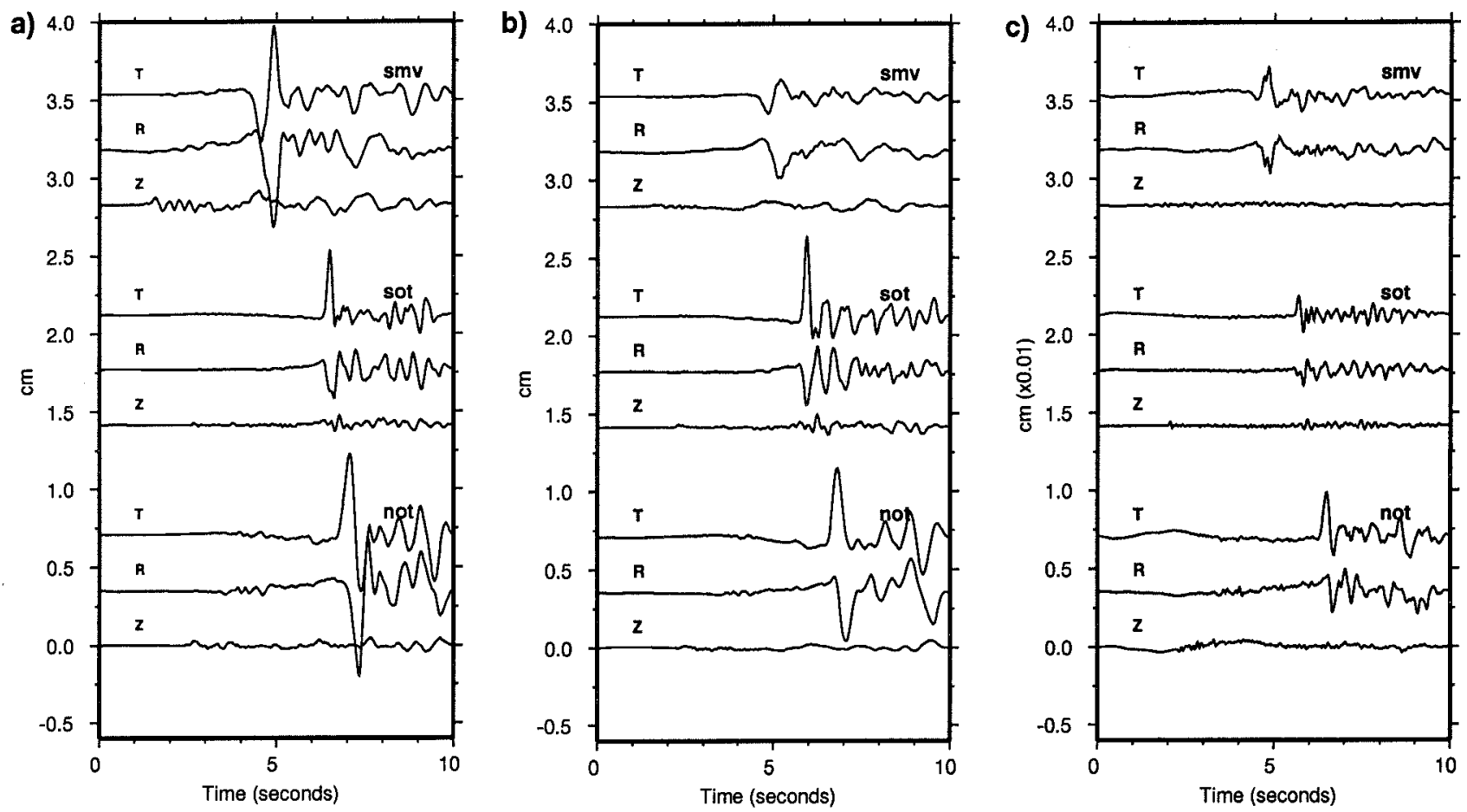

Figure 1. Transverse (T), radial (R), and vertical (Z) displacement waveforms at three stations SMV, SOT, and NOT for the two events studied and the aftershock used as the empirical Green's function are shown; (a) April 26, 1997, event, (b) April 27, 1997, event, and (c) the aftershock that occurred at $1110 \mathrm{UT}$ on April 26, 1997. Observe that the waveforms at station SOT are narrower than those at stations NOT and SMV for the two events as well as for the aftershock. This directivity effect is especially noticeable on the transverse ( $T$ ) component and suggests that the events ruptured toward station SOT. 


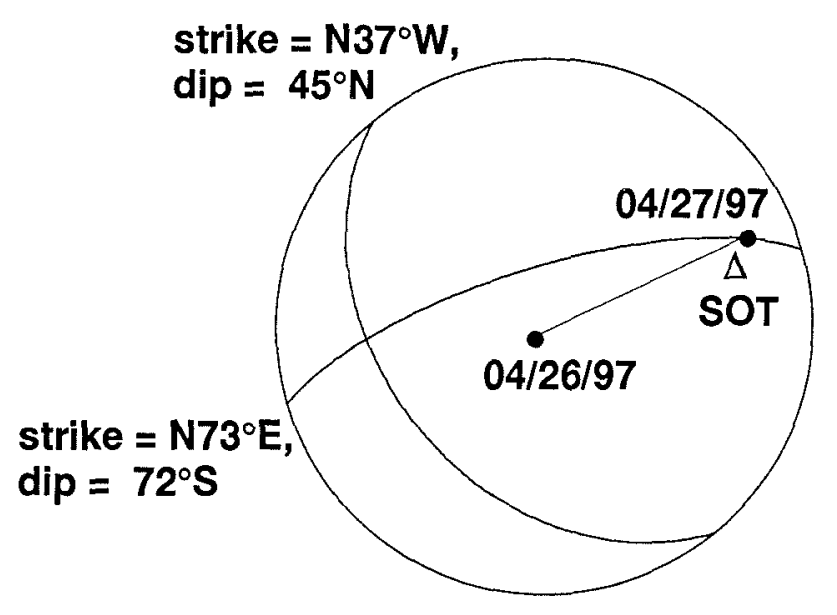

Figure 2. Location of the April 27 event relative to the April 26 event on the stereographic plot (upper hemisphere projection of the April 26 event), with the April 26 event at the center. The location of station SOT, which is at an azimuth of $N 75^{\circ} \mathrm{E}$ is marked.

tion of pulse widths similar to that observed for the two mainshocks. This variation could either be due to directivity or due to some difference in path effects, such as attenuation. However, since the aftershock pulses are narrow as compared to the mainshock pulses, this azimuthal variation in pulse widths would not significantly affect the deconvolution results.

\section{Focal Mechanisms}

The mechanisms and seismic moments for the two events (Plate 1 and Table 1) were obtained by a source inversion for $P n l$, Love, and Rayleigh waveform data [Zhu and Helmberger, 1996] at about 20 TriNet stations that had the best signal to noise ratio. These solutions, however, predict considerably larger amplitudes than those observed at the closest stations SOT, SMV, and NOT. This discrepancy is due to the soft layers beneath these stations. We used a velocity model with low-velocity surface layers (soil stations of Wald et al. [1996]) and found that essentially the same mechanisms explain the observed amplitudes. These mechanisms are shown in Plate 1 and are used throughout this study.

\section{Method}

\subsection{Empirical Green's Function Method}

To determine the source time functions (STFs), events at least one magnitude unit smaller than the mainshock, located within a few hundred meters of the mainshock, are used as empirical Green's functions [Hartzell, 1978; Frankel and Kanamori, 1983; Mori and Frankel, 1990; Mori, 1993]. These small aftershocks are considered as point sources in space and time such that their records consist of path and site effects only. The empirical Green's function (EGF) event is deconvolved from the mainshock event to remove the path and site effects from the mainshock record. The resulting waveform represents the far-field source time function of the mainshock. The deconvolution was performed using the following procedure:

1. A symmetric cosine taper was applied to both ends of the seismograms of the mainshock and the Green's function event. The records were band-pass filtered using a second-order Butterworth filter with corners at 0.05 and $20 \mathrm{~Hz}$. The data were again tapered.

2. We performed a deconvolution with a positivity constraint [Lawson and Hanson, 1974]. This yields a time series that is interpreted to be the far-field source time function of the mainshock, with the path and site effects removed.

We used the method described above to obtain source time functions for both $P$ and $S H$ waves. Several aftershocks were tried as empirical Green's functions (EGF), and the aftershock that occurred at 1110 UT on April 26, $1997\left(M_{w} \sim 2.7\right.$, two magnitude units smaller than the mainshock), was' selected for the waveform inversion because it has waveforms which are most similar to the mainshock waveforms and produces source time functions with high signal to noise ratios. We used the same aftershock as EGF for the April 26 and 27 events. About $2 \mathrm{~s}$ of the mainshock and aftershock data were used in the deconvolution.

Figure 3 shows the STFs obtained from $P$ and $S H$ waves by deconvolution with a positivity constraint. The positivity constraint is desirable because it yields nonnegative STFs. However, the method has a drawback in that any noise in the data tends to produce a long tail thereby broadening the STF. We believe that the STFs obtained using the deconvolution with a positivity constraint represent the overall time function, but the long tail is an artifact of the deconvolution.

\subsection{Waveform Inversion}

As mentioned earlier, the STFs at some stations have long tails which are probably artifacts of deconvolution. To minimize the effects of the tail on the inversion, we cut off the tails. As illustrated in Figure 4, we fit a function $(1-\cos (2 \pi \mathrm{t} / \mathrm{T})) / 2$ near the peak of the STF and truncate the STF at $t=0$ and $T$. We used the truncated STFs for the inversion.

To remove the effects of radiation pattern, we normalized the area of the truncated source time functions

Table 1. Velocity Model Used

\begin{tabular}{cc}
\hline$P$ Wave Velocity, $\mathrm{km} / \mathrm{s}$ & Depth, $\mathrm{km}$ \\
\hline 5.5 & $0-5.5$ \\
6.3 & $5.5-17.5$ \\
6.7 & $17.5-\infty$ \\
\hline
\end{tabular}

Modified from Hadley and Kanamori [1977]. 
S waves

P waves

April 26

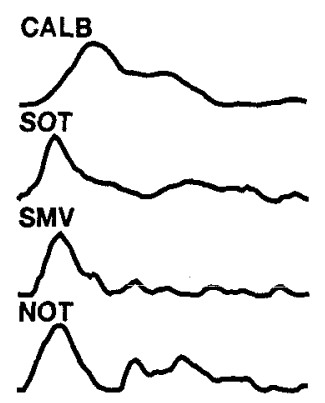

April 27
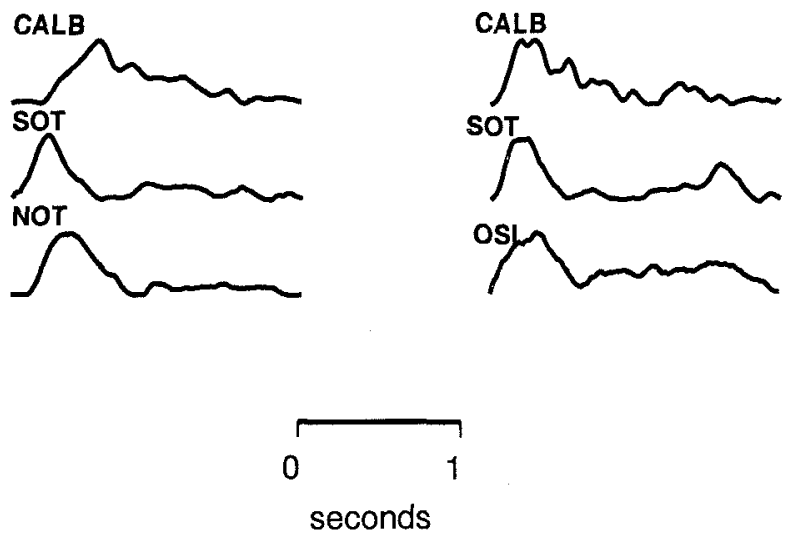

Figure 3. Waveforms at each station and the source time functions for the April 26, and April 27, 1997, events obtained using the positivity deconvolution.

at each station and used these to determine the slip distributions on both fault planes for each of the events. The method used here assumes a circular rupture propagating with a constant velocity across the fault. The fault plane is divided into triangular subfaults $0.5 \mathrm{~km}$ wide and $0.83 \mathrm{~km}$ high. Synthetic STFs for each subfault are calculated at each station [Spudich and Frazer, 1984], and the observed STF at each station is matched to the weighted sum of these sub-fault synthetics. The weights, which correspond to the slip distribution on the fault plane, are determined by a least squares inversion method with a positivity constraint [Lawson and Hanson, 1974], such that the error between the observed and synthetic STFs is minimized. The details of the method are described by Mori and Hartzell [1990]. The absolute values of slip are calculated by equating the moment obtained from the slip distribution to the moment obtained from the source inversion.

To compute the takeoff angles from each subfault to the stations, we used a modified Hadley-Kanamori ve-

locity model (Table 2). To avoid complications in the source model, the discontinuity at a depth of $16 \mathrm{~km}$ is moved to a depth of $17.5 \mathrm{~km}$ so that the rupture plane lies within a single velocity layer. We performed the inversion for a range of rupture velocities from 2.7 to 3.6 $\mathrm{kms}^{-1}$ for both nodal planes. These rupture velocities correspond to 0.74 to 0.99 times the shear velocity of $3.64 \mathrm{~km} / \mathrm{s}$ at the source depth of the model.

\section{Results}

The results of the waveform inversion for the April 26 and 27 events are shown in Figure 5. At each station, a set of three seismograms representing the observed displacement data and displacement synthetics for the shallowly dipping and steeply dipping planes is shown.

By comparing the data and synthetics we observe that for the April 27 event the steep plane fits the data marginally better than the shallow plane (e.g., the shallow plane is unable to fit the $P$ pulses at SOT and CALB, while the steep plane yields a better fit). For the April 26 event, though the steep plane fits the data slightly better, the difference in fit between the steep and shallow planes is not significant (Figure 5). We calculated the root mean square (rms) values of the misfit between the data and synthetics and normalized them by the average peak amplitude of the data. For the April 26 event these values are $12 \%$ for the steep plane and $14 \%$ for the shallow plane; for the April 27 event we obtained values of $13 \%$ for the steep plane and $9 \%$

S waves

April 26

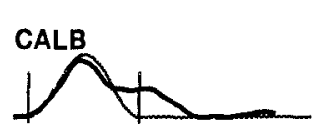

April 27
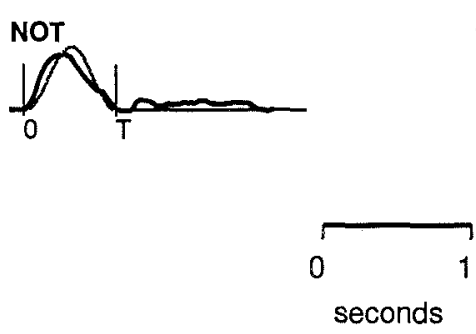

Figure 4. STFs obtained by deconvolution with a positivity constraint, which have long tails at some stations (e.g., the $S$ wave STF at station CALB and the $P$ wave STF at SOT) while the STFs at some stations lack such tails (e.g., the $P$ wave STF at SOT and the $S$ wave STF at NOT). The top traces show the results obtained by the deconvolution with a positivity constraint, while the bottom traces show the cosine functions used to truncate the long tails. 
Table 2. Focal Mechanism Solutions

\begin{tabular}{|c|c|c|c|c|c|c|c|}
\hline \multirow[b]{2}{*}{ Event } & \multirow[b]{2}{*}{ Depth, km } & \multicolumn{3}{|c|}{ Steeply Dipping Plane } & \multicolumn{3}{|c|}{ Shallowly Dipping Plane } \\
\hline & & Strike & Dip & Rake & Strike & Dip & Rake \\
\hline 970426103731 & 17.2 & $73^{\circ}$ & $72^{\circ} \mathrm{SE}$ & $54^{\circ}$ & $-40^{\circ}$ & $40^{\circ} \mathrm{NE}$ & $151^{\circ}$ \\
\hline 970427110920 & 16.9 & $65^{\circ}$ & $78^{\circ} \mathrm{SE}$ & $46^{\circ}$ & $-37^{\circ}$ & $45^{\circ} \mathrm{NE}$ & $163^{\circ}$ \\
\hline
\end{tabular}

The locations of the April 26 , and 271997 , events are $34.367^{\circ} \mathrm{N}, 118.674^{\circ} \mathrm{W}$ and $34.372^{\circ} \mathrm{N}, 118.650^{\circ} \mathrm{W}$, respectively.

for the shallow plane. The difference between the values for the shallow and steep planes is not large enough to allow determination of the slip plane. Thus the results of the waveform inversion alone cannot be used to determine the rupture plane. A rupture velocity of
$3.0 \mathrm{kms}^{-1}$ on the steeply dipping plane yields the best fitting solution for both the April 26 and 27 events.

The slip distributions on the steep planes of the April 26 and 27 events obtained from the inversion are shown in Figure 6. The hypocenter (marked $\mathrm{X}$ ) is at the cen- a)

S waves

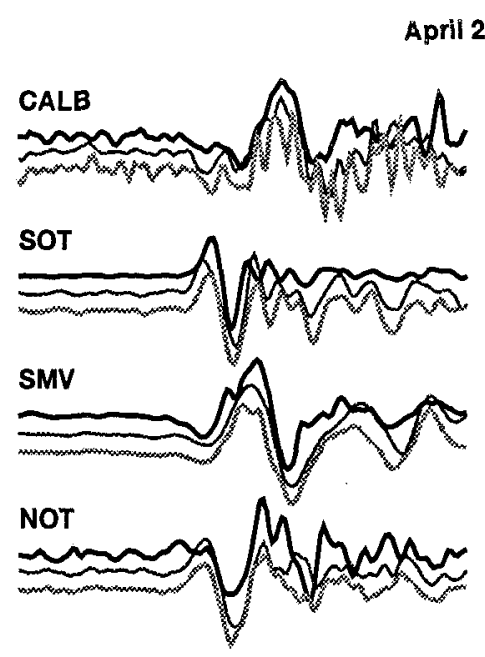

b)

P waves

April 27
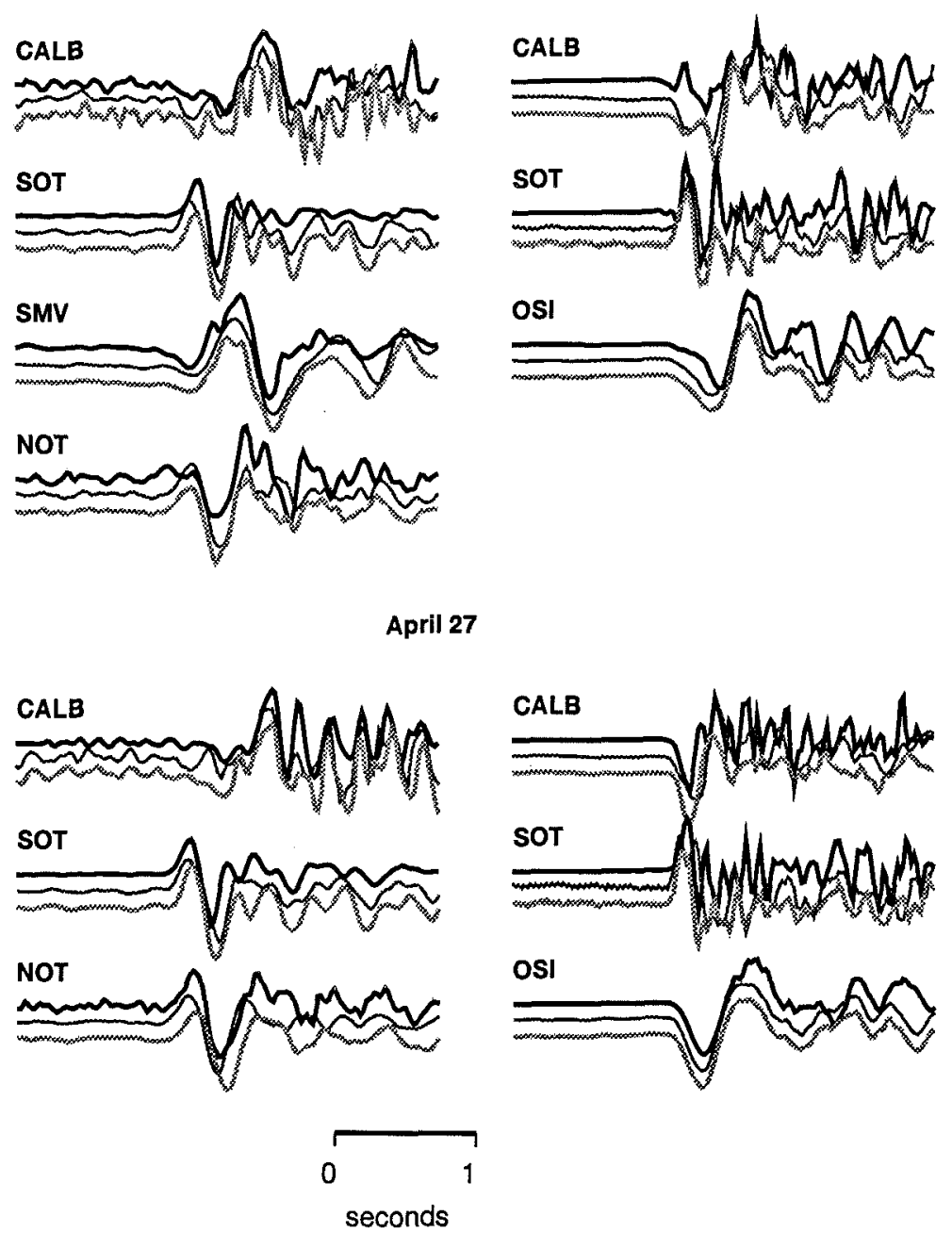

seconds

Figure 5. The top trace (thick line) at each station representing the displacement data for the mainshock at each station. The bottom two traces are synthetics for the shallow (thin line) and steep planes (shaded line) respectively computed by convolving the synthetic source time functions (obtained from the slip distribution on the fault planes) with the aftershock data. (a) Waveforms for April 26, 1997, event; (b) Waveforms for the April 27 event. 

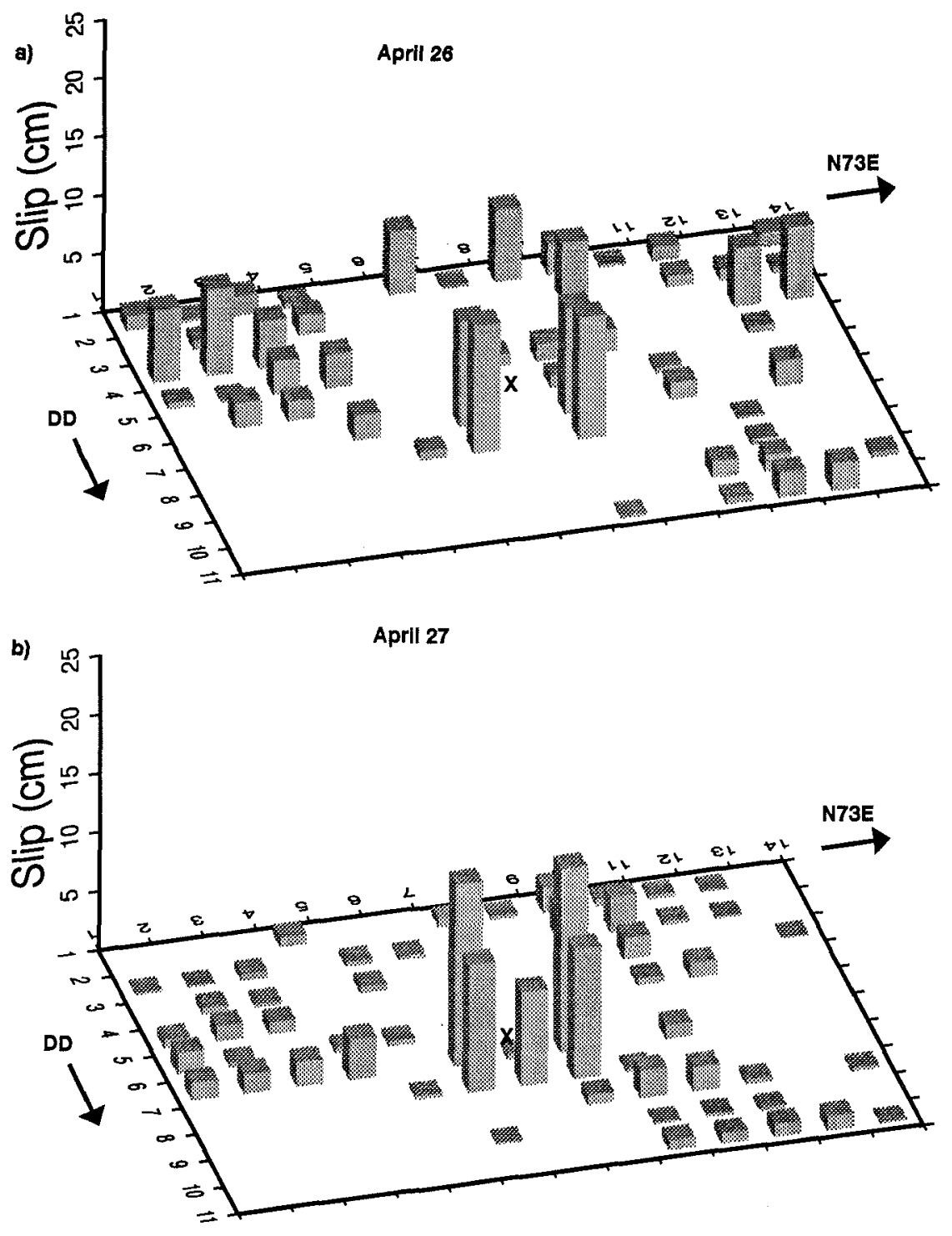

Figure 6.

Figure 6. (a) The slip distribution on the steeply dipping fault plane for the April 26, 1997, event. (b) The slip distribution on steeply dipping fault plane for the April 27, 1997, event. Each square corresponds to a triangular subfault $0.5 \mathrm{~km}$ wide and $0.83 \mathrm{~km}$ tall. $\mathrm{X}$ denotes the location of the hypocenter on the fault plane. The downdip direction is marked by DD, and the strike of the plane is indicated.

ter of the fault plane. For both events, most of the slip is concentrated in a small area around the hypocenter with very small amounts of slip in the rest of the fault plane. For the April 27 event, if we take the five subfaults where the slip is largest, the average slip, $D$, is $\sim 12 \mathrm{~cm}$, and the rupture area is $1.04 \mathrm{~km}^{2}$. For a circular rupture the stress drop, $\Delta \sigma$ is given by [Eshelby, 1957; Keilis Borok, 1959]

$$
\Delta \sigma=\frac{7}{16} \mu \frac{D}{(\text { area } / \pi)^{\frac{1}{2}}},
$$

where $\mu=3 \times 10^{11}$ dyncm $^{-2}$. Using $D=12 \mathrm{~cm}$, and area is $1.04 \mathrm{~km}^{2}$, we obtain $\Delta \sigma=30$ bars. For the
April 26 event, if we consider the four sub-faults where the slip is largest, the average slip, $D$, is $\sim 10 \mathrm{~cm}$, the rupture area is $0.83 \mathrm{~km}^{2}$, and the calculated stress drop, $\Delta \sigma$ is 25 bars. The inversion cannot resolve the distinct pulses of the double event of the April 27 event. Hence the calculated stress drops are lower limits; the actual stress drops could be higher.

\section{Aftershock Relocations}

Distributions of hypocenters of aftershocks can often be used to determine the orientation of rupture planes. In the Northridge aftershock region, however, the pattern of aftershocks is quite complicated and does not 
clearly indicate a strong regional trend. Plate $1 \mathrm{~b}$ shows a cross section of all the well-located aftershocks in the region that were recorded by the Southern California Seismic Network from January 1994 through April 1997. The gray box in the Plate la shows the area and orientation of the cross section. The events were relocated using a local three-dimensional velocity model that was derived by simultaneously relocating a subset of 748 events and solving for the velocity structure. We used the program SIMULPS by Eberhart-Phillips [1993] with a $7 \times 4$ horizontal grid of $1 \mathrm{~km}$ spacing and eight depth layers.

In this western region of the Northridge aftershock zone, the events prior to April 1997 generally show a broad pattern dipping toward the north (black dots), while the events of April 1997 sequence (purple dots) show a trend dipping steeply to the south, similar to the trend shown by the aftershocks of the 1971 San Fernando earthquake (shown in red). Several smaller seismicity clusters illuminate other structures in the region.

\section{Discussion and Conclusions}

Although the waveform data cannot distinguish the rupture plane from the auxiliary plane, the relative relocation of the April 26 and April 27 events, the trend of the aftershocks of these events, and the directivity toward station SOT suggest that the whole sequence ruptured on a south dipping steep plane that coincides with the steep nodal plane of the April 26 and the April 27 events. It is interesting to note that Plate 1 shows no obvious south dipping plane of seismicity in the epicentral region prior to the April 1997 sequence. The seismicity pattern of the events that occurred between January 1994 and April 1997 (black dots) suggests the existence of a north dipping rupture plane, similar to that of the 1971 San Fernando earthquake. However, the April 1997 sequence ruptured on a plane that is almost perpendicular to the plane of background seismicity in the region. It is important to note that the north dipping plane of background seismicity (black dots) is opposite to the trend of the Northridge mainshock (blue dots). We also observe smaller clusters of seismicity, which suggest the presence of other structures with different orientations in the region. Thus this study shows that the deformation beneath the Transverse Ranges occurs on a complex array of rupture planes. The complexity of the seismogenic structure in this region has been suggested previously, e.g., the fault plane of the 1971 San Fernando earthquake is nearly perpendicular to that of the 1994 Northridge earthquake [Hauksson et al., 1995; Mori et al., 1995]. Our study provides evidence that shows that the complex seismogenic structure at depth beneath the Transverse Ranges exists on much smaller scales too, i.e., at scales of a few kilometers. The rupture area for both the April 26 and 27 events is $\sim 1 \mathrm{~km}^{2}$ with a stress drop of at least 20 to 30 bars.
Acknowledgments. This research was supported by the USGS grant USGS.HQGR0035 and the Southern California Earthquake Center (SCEC). SCEC is funded by NSF Cooperative Agreement EAR-8920136 and USGS Cooperative Agreements 14-08-0001-A0899 and 1434-HQ-97AG01718. This is SCEC contribution 460. Contribution 8619 of the Division of Geological and Planetary Sciences, California Institute of Technology, Pasadena.

\section{References}

Anderson. D. L., The San Andreas fault, Sci. Am., 225(5), 53-68, 1971.

Bird, P., and R. W. Rosenstock, Kinematics of present crust and mantle flow in southern California, Geol. Soc. Am. Bull., 95, 946-957, 1984.

Cheadle, M. J., B. L. Czuchra, T. Byrne, C.J. Ando, J. E. Oliver, L.D. Brown, S. Kaufman, P.E. Malin, and R. A. Phinney, The deep crustal structure of the Mojave Desert, California, from COCORP seismic reflection data, Tectonics, 5, 293-320, 1986.

Corbett E. J., and C. E. Johnson, The Santa Barbara, California, earthquake of 13 August 1978, Bull. Seismol. Soc. Am., 72, 2201-2226, 1982.

Davis, T. L., and J. Namson, A balanced cross-section of the 1994 Northridge earthquake, southern California, Nature, 372, 167-169, 1994.

Donnellan A., B. H. Hager, and R. W. King, Discrepancy between geological and geodetic deformation rates in the Ventura basin, Nature, 366, 333-336, 1993.

Eberhart-Phillips, D., Local earthquake tomography: earthquake source regions, in Seismic Tomography: Theory and Practice, edited by H.M. Iyer and K. Hirahara, pp. 613643, Chapman and Hall, New York, 1993.

Eshelby, J.D., The determination of the elastic field of an ellipsoidal inclusion and related problems, Proc. $R$. Soc. London, Ser. A, 241, 376-396, 1957.

Frankel, A., and H. Kanamori, Determination of rupture duration and stress drop for earthquakes in southern California, Bull. Seismol. Soc. Am., 73, 1527-1551, 1983.

Hadley, D., and H. Kanamori, Seismic structure of the Transverse Ranges, California, Geol. Soc. Am. Bull., 88, 1469-1478, 1977.

Hadley, D., and H. Kanamori, Recent seismicity in the San Fernando region and tectonics in the west-central Transverse Ranges, California, Bull. Seismol. Soc. Am., 68, 1449-1457, 1978.

Hartzell, S. H., Earthquake aftershocks as Green's functions, Geophys. Res. Lett., 5, 1-4, 1978.

Hauksson, E., L. M. Jones, and K. Hutton, The 1994 Northridge earthquake sequence in California: Seismological and tectonic aspects, J. Geophys. Res., 100, 12335-12355, 1995.

Huang, W., L. T. Silver, and H. Kanamori, Evidence for possible horizontal faulting from earthquake mechanisms, Geology, 24, 123-126, 1996.

Humphreys, E., R. W. Clayton, and B. H. Hager, A tomographic image of the mantle structure beneath southern California, Geophys. Res. Lett., 11, 625-627, 1984.

Jackson, J., and P. Molnar, Active faulting and block rotations in the western Transverse Ranges, California, $J$. Geophys. Res., 95, 22,073-22,087, 1990.

Keilis Borok, V., On estimation of the displacement in an earthquake source and of source dimensions, Ann. Geofis., 12, 205-214, 1959.

Lawson, C. L., and R. J. Hanson, Solving Least Squares Problems, 340 pp., Prentice-Hall, Englewood Cliffs, N. J., 1974.

Mori, J., Fault plane determinations for three small earth- 
quakes along the San Jacinto fault, California: Search for cross faults, J. Geophys. Res., 98, 17,711-17,722, 1993.

Mori, J., and A. Frankel, Source parameters for small events associated with the 1986 north Palm Springs, California, earthquake determined using empirical Green functions, Bull. Seismol. Soc. Am., 80, 278-295, 1990.

Mori, J., and S. Hartzell, Source inversion of the $1988 \mathrm{Up}-$ land, California, earthquake: Determination of a fault plane for a small event, Bull. Seismol. Soc. Am., 80, 507$518,1990$.

Mori, J., D. J. Wald, and R. L. Watson, Overlapping fault planes of the 1971 San Fernando and 1994 Northridge, California earthquakes, Geophys. Res. Lett., 22, 10331036, 1995.

Mori. J., H. Kanamori, J. Davis, E. Hauksson, R. Clayton, T. Heaton, L. Jones, A. Shakal, and R. Porcella, Major improvements in progress for southern California earthquake monitoring, Eos Trans. AGU, 79, 217, 221, 1998.

Namson, J., and T. L. Davis, Seismically active fold and thrust belt in the San Joaquin Valley, central California, Geol. Soc. Am. Bull., 100, 257-273, 1988a.

Namson, J., and T. L. Davis, A structural transect of the western Transverse Ranges, California: Implications for lithospheric kinematics and seismic risk evaluation, Geology, 16, 675-679, 1988b.

Nicholson, C., L. Seeber, P. Williams, and L. R. Sykes, Seismicity and fault kinematics through the eastern Transverse Ranges, California: Block rotation, strike-slip faulting, and low-angle thrusts, J. Geophys. Res., 91, 48914908, 1986.

Ryberg, T., and G. S. Fuis, The San Gabriel Mountains bright reflective zone: Possible evidence of young midcrustal thrust faulting in southern California, Tectonophysics, 286, 31-46, 1998.

Savage, J. C., W. H., Prescott, and G. H. Gu, Strain accumulation in southern California, 1973-1984, J. Geophys. Res., 91, 7455-7473, 1986.

Spudich, P., and L. N. Frazer, Use of ray theory to calculate high-frequency radiation from earthquake sources having spatially varying rupture velocity and stress drop, Bull. Seismol. Soc. Am., 74, 2061-2082, 1984.
Thatcher, W., Episodic strain accumulation in southern California, Science, 194, 691-695, 1976.

Wald, D., T. Heaton, and K. W. Hudnut, The slip history of the 1994 Northridge, California, earthquake determined from strong ground motion, teleseismic, GPS, and leveling data, Bull. Seismol. Soc. Am., 86, S49-S70, 1996.

Webb, T. H., and H. Kanamori, Earthquake focal mechanisms in the eastern Transverse Ranges and San Emigdio Mountains, southern California and evidence for a regional decollement, Bull. Seismol. Soc. Am., 75, 737-757, 1985.

Yeats, R. S., Quaternary flake tectonics of the California Transverse Ranges, Geology, 9, 16-20, 1981.

Yeats, R. S., Large-scale Quaternary detachments in the Ventura basin, southern California, J. Geophys. Res., 88, $569-583,1983$.

Yeats, R. S., Converging more slowly, Nature, 366, 299-301, 1993.

Yeats, R. S., G. J. Huftile, and L. T. Stitt, Late Cenozoic tectonics of the east Ventura basin, Transverse Ranges, California, AAPG Bull., 78, 1040-1074, 1994.

Zhu, L., and D. V. Helmberger, Advancement in source estimation techniques using broadband regional seismograms, Bull. Seismol. Soc. Am., 86, 1634-1641, 1996.

H. Kanamori and A. Venkataraman, 252-21, Seismological Laboratory, California Institute of Technology, Pasadena, CA 91125. (hiroo@gps.caltech.edu; anupama@gps.caltech.edu)

J. Mori, Disaster Prevention Research Institute Kyoto University Gokasho, Uji, Kyoto 611-0011 Japan. (mori@rcepgw.rcep.dpri.kyoto-u.ac.jp)

L. Zhu, Department of Earth Sciences, University of Southern California, Los Angeles, CA 90089-0740. (lupei@usc.edu)

(Received February 22, 1999; revised February 11, 2000; accepted February 23, 2000.) 